\title{
The European Electricity Market and Cross-Border Transmission
}

\author{
M. Adamec, M. Indráková, M. Karajica
}

This paper deals with basic characteristics and features of trading in electricity, especially in cross-border trading. First, the most important features of electricity as a commodity are explained, with the consequences for electricity trading. Then characteristics and changes in the electricity market after liberalization are discussed. This liberalization has taken place throughout Europe, and the consequences of this revolutionary change are still visible.

The main features of electricity trading are mentioned in general. Then cross-border trade in Europe is discussed in greater detail. In this context the basic principles of the allocation of cross-border transmission capacities are explained.

The next part of the paper considers the characteristics of the European electricity market from the trader's point of view. Liquidity as a very important index is introduced here.

Finally the most visible trends in cross-border trade and the most probable future development in this area are presented.

Keywords: Auction, congestion, electricity, ESS, KISS, MO, scheduling, TPA, TSO, Unbundling, SB.

\section{Types of electricity market bases}

The electricity market is determined by the main characteristic of electricity i.e., that it cannot be stored. Due to this feature, it is necessary to transmit and retail the currently produced electricity immediately. As a result time optimalization of energy retailing is impossible.

This feature has a fundamental influence on the energy markets, or more precisely on the trading systems. There are some standards for electricity trading [1].

1) SB (Single Buyer): The single buyer is the only subject that can buy the electric energy. SB buys the electricity at the lowest cost from the producers and then it sells this electric energy on to customers. The disadvantage of this model is the exclusive privilege of the one and only subject for purchasing the electric energy. Therefore it is not often used in Europe. (One exception is Belarus and until recently, France.)

2) TPA (Third Party Access): Access of third parties to the transmission net. This means the right for every customer or producer to free energy transportation via the transmission system.

- rTPA (Regulated Third Party Access): This assumes bilateral contracts between market subjects (producers, traders and customers) for energy retail on condition of regulated prices. The existence of a regulatory authority is assumed at the same time. This authority designates prices in non-liberalized segments of the power industry. rTPA exists in most European countries.

- nTPA (Negotiated Third Party Access): Access to the nets on condition of negotiated prices. (This basis was applied in Germany, but since 2005 Germany has switched to the rTPA standard.)

Due to the impossibility of storing electric power, its price is highly volatile on spot markets (Fig. 1.), and this forces investors to use some form of hedging (risk management). The use of derivates (futures, forwards) is in the power industry very common. (Experience from long term liberalized markets shows that derivates reduce spot prices [2].)

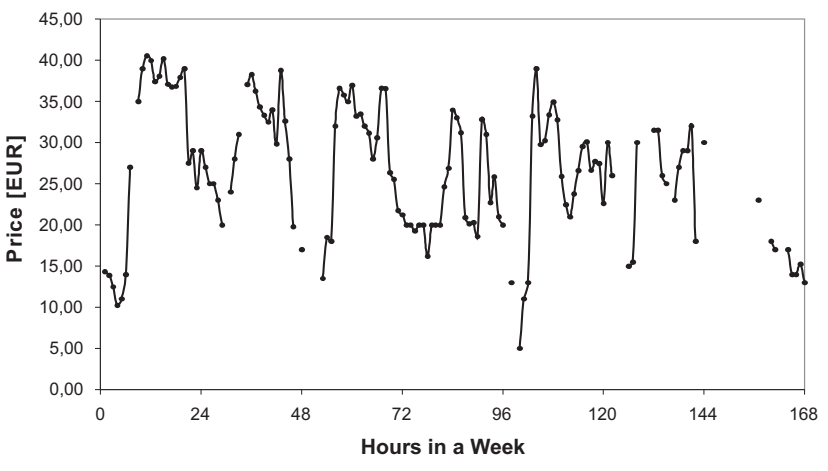

Fig. 1: Price of electricity during one week on EEX

\section{Electric energy market}

In order to liberalize energy markets it is necessary to divide up large companies, which were integrated in the past. Production, transmission and trading of electricity need to be separated. In addition, this liberalization establishes free economic competition in the production and trading sectors. The only monopoly that remains is in the electric power transmission and distribution grid. The prices in these sectors are determined by the above-mentioned regulatory authority. This forced division of particular structures in the power industry is called Unbundling (Fig. 2).

\subsection{Ways of trading in electricity}

There are two main markets, in which electric power is traded. Firstly, on OTC (Over-The-Counter) market and secondly on the classical exchange. On such markets electricity is traded as well as electricity derivates. From trader's point of view it is better to trade on the exchange. There are two main reasons for this. Firstly dealing on the exchange is better assured, and secondly, the exchange has better liquidity for each trader. This liquidity provides opportunities for speculative deals. German, Austrian and Dutch markets are very popular for energy traders because of their liquidity. Liquidity is discussed in greater detail in section three of this paper. 

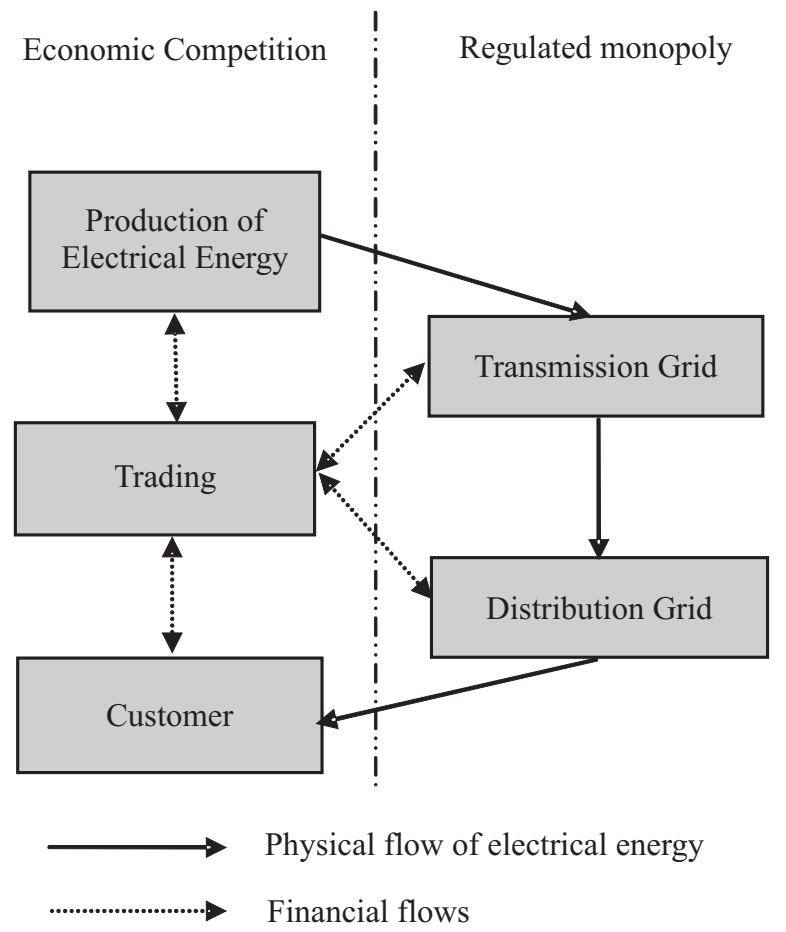

Fig. 2: Division of the electricity market between liberalized and regulated parts (Unbundling)

\subsection{Specifics of cross-border trade}

Cross-border trade electric power in Europe is enabled by integration of the countries into UCTE (Union for the Coordination of Transmission of Electricity). This union facilitates the sale electric power from one state to another. The major remaining is of congestion on the maost of the borders, leading to insufficient transfer capacity between countries.

The existence of this congestion has led to the development of methods for allocating free capacity to particular parties interested in electricity transmission.

\subsubsection{Capacity allocation methods}

If there is no congestions at the border, it is not necessary to allocate free capacity and every bid for transmission capacity is accepted tax-free. ( For example, the Austrian - German border.)

Problems occur on borders where the capacity of the cross-border lines is insufficient for all bids. In such cases the following principles are used for allocating free capacity.

\section{Non-market based principles}

First-come-first-serve - This guarantees the allocation of capacity to customers in the same order as they send their requests.

Pro rata - When the demand is higher than the free capacity, each request is reduced proportionally, so that no congestion remains. No request is refused, but none is accepted to the full extent.

\section{Auction Principles}

Explicit auction - This is the most widely used way of allocating capacity in Europe. Each TSO (Transmission System
Operator) sets the free capacity ex ante, and this capacity is allocated by auction. Bids are sorted according to their price, and they are accepted until no free capacity remains. The price of each successful request for capacity can be the same as the bid in the auction ("Pay-As-Bid"), or it could be equal to the lowest accepted bid ("Marginal Bid Auction").

Implicit auction - The difference from an explicit auction is that the price for the capacity is included directly in the price of the transmitted energy. The price for the capacity (as a part of the transmitted energy price) is set by MO (Market Operator) in such way that the amount of the accepted bids does not exceed over the free capacity. MO knows bids from each participant in the market and can therefore set the exact conditions under which the bid can still be accepted. The auction is arranged, and the revenue from it belongs, not to TSO (difference from explicit auction) but to MO.

Market splitting - It is developed implicit auction procedure. The electrical energy is transmitted in such way that electricity from areas with lower prices is transmitted to areas with higher prices. Thus prices in areas with lower prices level on with those in areas with higher prices. (This process is like splitting of market from one area to another. The whole auction process has acquired its name from this similarity.). $\mathrm{MO}$ in one country manages the markets on both sides of the border by a market splitting process, so very close cooperation is necessary between the two MOs.

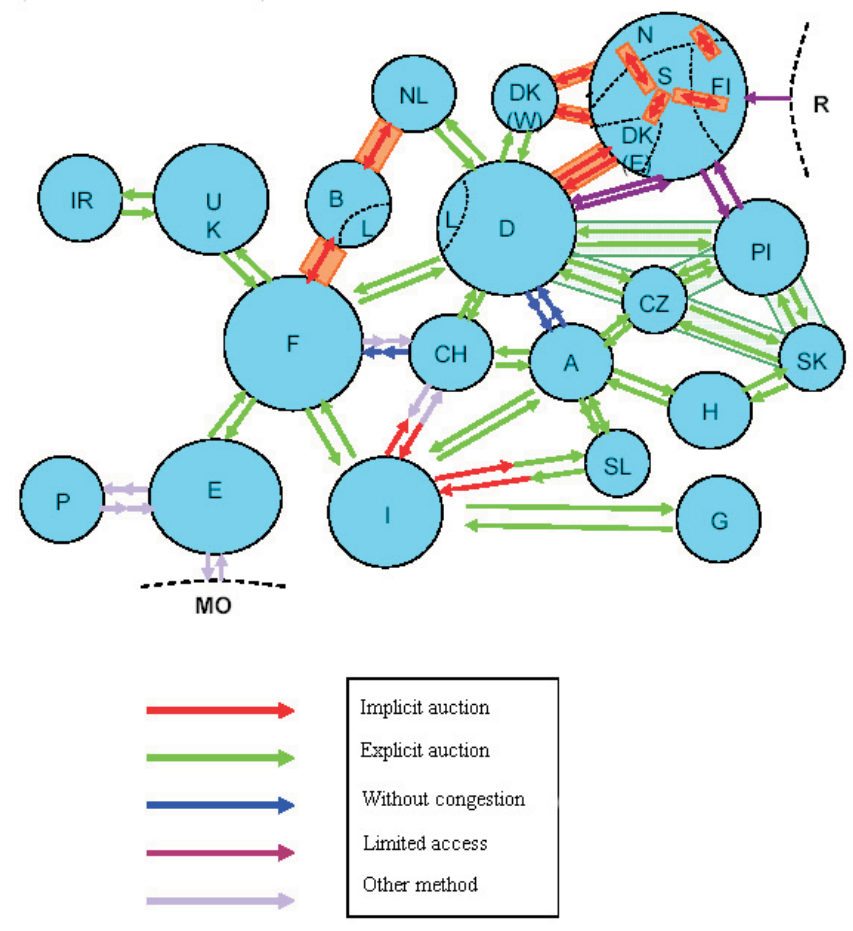

Fig. 3: Types of congestion management

\subsubsection{Communication between Market Participants}

Due to congestion on borders, it is necessary to schedule of every energy cross-border transport from energy traders. Every energy trader must therefore communicate in real time with the subjects allocate the cross-border capacities. This communication is carried out mostly on-line and automati- 
cally. Each market participant has its own EIC (ETSO Identification Code), unique for each country, provided by the appropriate issuing office (mostly TSO).

Communication is carried out in various ways. In areas with poor access to free trade, phone and fax communication are widely used for announcing the bids. However, in western Europe on-line communication prevails. This on-line communication consists in automatic file sending, mostly in XML or XLS format.

The KISS Method (Keep It Small and Simple) - This method sends data files in XLS format (MS EXCEL 97). These files contain information about exact energy transmission characteristics, e.g. time or amount of transmitted energy.

The ESS Method (ETSO Scheduling System) - This method uses a special XML format for using data files. It is the newest way to communicate on electricity markets. (This is currently used in Germany, Austria, Luxemburg, Switzerland, Hungary, Poland, the Czech Republic, Slovakia, France, Slovenia, Croatia and Rumania.)

In connection with cross-border transmission capacities, the following relations between particular categories of capacities have been introduced:

$$
\mathrm{NTC}=\mathrm{TTC}-\mathrm{TRM} \text {, }
$$

where TTC (Total Transfer Capacity): Expected maximum quantity of generated energy, that can be transmitted between the two countries that does not limit the system or set limits on the one party. The safety limits for the following considerations have to be taken into account:

- maximum warming of conductors,

- maximum level of voltage in a particular system,

- limit of stability (mechanical and dynamic limitations).

The TTC values are calculated using the ETSO predictive model. TRM (Transmission Reliability Margin) is a precautionary reserve that takes into account unpredictable developments due to insufficient provision of information to ETSO from parties of subjects dealing in the markets. In connection with NTC we should mention ATC (Available Transfer Capacity), which introduces true available capacity, defined as the difference between NTC and long-term reserved capacities.

\section{Market liquidity}

So-called liquidity is a significant indicator of market attractiveness from the viewpoint of a trader. There is no generally valid definition of market liquidity, but it is very often calculated in practice on the basis of the following relation:

Liquidity of the Energy Market $=\mathrm{TTE} / \mathrm{TGE}$,

where TTE (Total Traded Energy) is the total quantity of electricity marketed on the commodity exchange of the corresponding market, and TGE (Total Generated Energy) is the total quantity of energy produced on the corresponding territory. The following table indicates the liquidity of the markets in selected EU countries.

It should be pointed out in connection with liquidity that this indicator may have considerably higher values, as the same electricity may be marketed several times and, more-
Table 1: Overview of liquidity on individual markets [5]

\begin{tabular}{|l|c|c|c|}
\hline \multicolumn{1}{|c|}{ Country } & $\begin{array}{c}\text { Total } \\
\text { Generated } \\
\text { Energy [TWh] }\end{array}$ & $\begin{array}{c}\text { Total } \\
\text { Traded } \\
\text { Energy [TWh] }\end{array}$ & $\begin{array}{c}\text { Liquidity } \\
{[\%]}\end{array}$ \\
\hline Germany & 445.1 & 39.0 & 8.76 \\
\hline Austria & 51.8 & 1.0 & 1.93 \\
\hline Slovakia & 26.0 & 0.36 & 1.38 \\
\hline France & 554.0 & 7.5 & 1.35 \\
\hline Poland & 110.9 & 1.1 & 0.99 \\
\hline Italy & 322.0 & 2.0 & 0.62 \\
\hline Czech Republic & 61.4 & 0.3 & 0.49 \\
\hline
\end{tabular}

over, electricity manufactured in another country may be marketed on the corresponding commodity exchange.

\section{Overview of electric power flows}

Europe will be facing shortages of electric power on a medium-term and long-term basis. If the consumption of electric power grows by more than two per cent a year (which is considered to be a rather conservative estimate), there will be a shortfall in manufacturing capacity of about $250 \mathrm{GWh}$ in Europe twenty years from now. This is the output of approximately 125 power stations of the size of Temelín.

The common market in Europe has been generated as a direct consequence of the European Union's effort to liberalize the market for electric power, and to suppress the natural monopoly in power engineering. This not only enables competition on domestic markets but is also part of the effort to interconnect individual markets within Continental Europe,

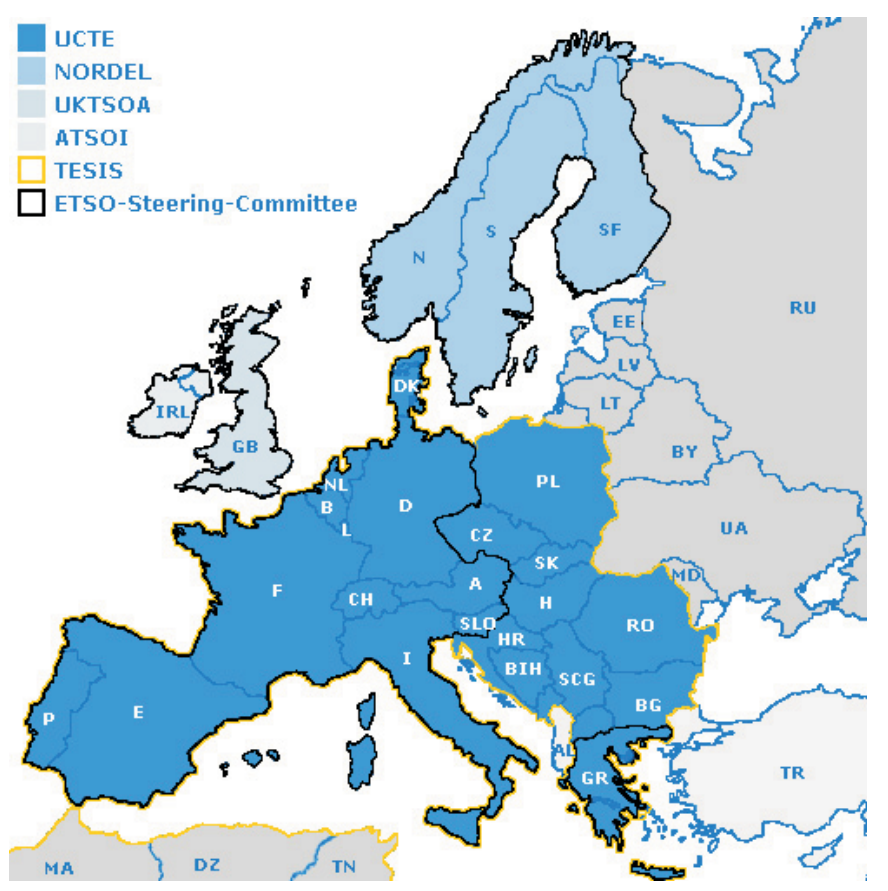

Fig. 4: Map of European associations which associate the TSOs of different countries 
with the British, Isles and with the states of Northern Europe. This has formed the basis for some associations of TSOs (Transmission System Operators) set up in individual countries. The most important such organizations are ETSO
(European Transmission System Operator) and UCTE (Union for the Coordination of Transmission of Electricity). These organizations are becoming less significant with the gradual spread of liberalization.

Table 2: Annual balance of power in individual European countries in 2005

\begin{tabular}{|c|c|c|c|c|}
\hline Country & $\begin{array}{c}\text { Generation } \\
\text { [TWh] }\end{array}$ & $\begin{array}{c}\text { Annual } \\
\text { consumption } \\
\text { [TWh] }\end{array}$ & $\begin{array}{l}\text { Import } \\
\text { [TWh] }\end{array}$ & $\begin{array}{l}\text { Export } \\
\text { [TWh] }\end{array}$ \\
\hline Belgium & 83.3 & 83.8 & 14.3 & 8.0 \\
\hline Belarus & 30.7 & 34.7 & 9.0 & 5.0 \\
\hline Bosnia Herzegovina & 12.71 & 10.92 & 2.17 & 3.58 \\
\hline Bulgaria & 43.92 & 36.462 & 0.799 & 8.380 \\
\hline Montenegro & 2.724 & 4.534 & 1.819 & 0.0 \\
\hline Czech Republic & 82.579 & 62.691 & 12.351 & 24.985 \\
\hline Estonia & 9.949 & 6.914 & 0.345 & 1.894 \\
\hline France & 549.2 & 482.4 & 32.3 & 90.9 \\
\hline Croatia & 11.6 & 16.7 & 8.8 & 3.6 \\
\hline Italy & 303.0 & 309.8 & 5.03 & 1.1 \\
\hline Lithuania & 14.8 & 10.1 & 1.1 & 4.1 \\
\hline Latvia & 4.723 & 6.871 & 5.087 & 2.940 \\
\hline Hungary & 35.7 & 34.6 & \multicolumn{2}{|c|}{ Import/Export saldo $6.2 \mathrm{TWh}$} \\
\hline Macedonia & 6.475 & 8.089 & 1.659 & 0.045 \\
\hline Germany & 581.3 & 563.6 & 53.4 & 61.9 \\
\hline Netherlands & 94.4 & 114.7 & 27.346 & 5.887 \\
\hline Poland & 143.95 & 130.06 & 5.00 & 16.19 \\
\hline Portugal & 41.7 & 47.9 & 9.6 & 2.8 \\
\hline Austria & 66.359 & 69.024 & 20.397 & 17.732 \\
\hline Romania & 54.804 & 51.889 & 1.605 & 4.520 \\
\hline Greece & 49.6 & 53.4 & 5.6 & 1.8 \\
\hline Slovakia & 29.1 & 26.3 & 8.6 & 11.3 \\
\hline Slovenia & 13.289 & 12.389 & 5.833 & 6.026 \\
\hline Serbia & 39.3 & 38.1 & 7.9 & 9.1 \\
\hline Spain & 263.32 & 246.19 & 8.09 & 9.41 \\
\hline Switzerland & 55.287 & 61.637 & 37.298 & 29.828 \\
\hline Turkey & 162.0 & 160.8 & 1.8 & 0.6 \\
\hline Ukraine & 185.236 & 176.884 & 0.0 & 8.351 \\
\hline Albania & 5.409 & 5.933 & 0.643 & 0.119 \\
\hline The Russian federation & 952.0 & 939.6 & 9.9 & 22.3 \\
\hline
\end{tabular}


- UCTE: Union for the Coordination of Transmission of Electricity,

- NORDEL: Organisation for the Nordic Transmission System Operators,

- UKTSOA: The Power System of the United Kingdom,

- TESIS: Trans-European Synchronously Interconnected System,

\section{- ETSO: European Transmission System Operator}

Table 2 shows the balance of electric power in individual countries in Europe.

The largest quantity of electric power is produced in Germany and in France. These countries are followed by Great Britain and Italy, but with production lower by more than 170 TWh. Germany, unlike France, consumes almost all of the electric power that it produces. France is thus the largest exporter of electricity at present. The Czech Republic takes the second place. However, it should be pointed out that the surplus of electric power in the Czech Republic is a short-term one. The service life of desulphurized coal-fired power plants will end in about 2010. The largest importers of electric power are the Benelux countries and Hungary. Hungary covers $18 \%$ of its requirements through importing.

\section{Conclusions}

Over several recent decades, worldwide power consumption has continued to grow strongly. There is now increasing awareness of the finiteness and scarceness of resources. Emphasis is now being placed on efficient exploitation of electric power. In order to achieve effective exploitation of electrical power, several measures have been taken and new tools have been introduced.

One of the most significant tools is implementation of market value of electric power, which reflects its real costs or, more precisely, the maximum price that is acceptable for the end consumer. In the most advanced countries in the world, stock exchange trading in electric power is now common. However, stock exchanges dealing with electric power are not common in less mature countries. Traders in electric power aim to achieve maximum profit from the sale of electricity, and in this way a double effect is achieved. Firstly, they exert indirect pressure on producers by requiring a low purchase price for electric power. The result is efficient exploitation of primary commodities, technologies and other inputs necessary for generating electricity. Secondly, they exert indirect pressure on the end consumer by maximizing the selling price. The result is efficient exploitation of electric power, as the end consumer is motivated to minimize consumption.

Another tool for efficient exploitation of electric power is the effort to increase efficiency in the all parts of the electric supply chain, from generation, transmission and distribution to the dealing in electric power. The result of this effort has reformed the power sector in a series of EU member countries. Previously there had been power companies dealing with the whole electric supply chain, from generation, transmission, distribution and sale of electric power. However, in the course of time it turned out that this model is ineffective. Strict separation of generation, transmission, distribution and dealing in electric power (unbundling) has now been introduced. An- other distinctive tool is the opening of access to the grid by third parties, i. e. implementation of the rTPA market platform, the purpose of which is to increase competition. It should be emphasized, however, that several of the less mature European countries have implemented the legislation for the rTPA market platform, but in practice they still really use the SB market platform. Implementation of the rTPA platform requires a long-term perspective.

A significant tool in support of intrastate dealing in electricity is the implementation of an electric power stock exchange marketed on yearly, monthly, weekly or daily levels through a range of different types of products. Comparing cross-border trading intrastate trading, auctions on cross-border transmission capacities are held mostly monthly or daily and in some cases weekly. These auctions are mostly arranged by operators of transmission systems, or by also called scheduling offices. The emergence of international auction (scheduling) offices should simplify trading in cross-border transmission capacities. It is necessary to emphasize the distinction between real physical flows of electric and financial flows related to business transactions. For this reason, there is pressure to use a Flow-based method, that will take into account real physical flows. Implementing this method will restric business, since option transmission cross-border profiles will be determined by this method.

We should also mention here trading in emission allowances, though this is not at present a great influence on trading in electric power. The main reason is that in the first allocation period the allocated emission allowance was greater than the needs of individual countries. This led to the collapse of the market in emission allowances. However, increase in the volume of trading in emission allowances, due to decrease the emission limits, could cause higher price of emission allowances and electric power.

This trend should lead to the future electricity generation in countries where electric power can be generated more cheaply and more efficiently. This will lead to stronger cross-border trade in electric power, resulting in the establishment of many regional stock exchanges or in the last resort in the establishment of a global stock exchange for electric power. As fuel for generating becomes scarcer, exchanges will be established for various fuel types.

\section{Acknowledgments}

The authors would like to express their gratitude to their supervisors, Prof. Ing. Oldřich Starý, CSc. and Doc. Ing. Jaromír Vastl, CSc. for valuable comments and contributions.

\section{References}

[1] Training documents of the Department of Economics, Management and Humanities, FEE CTU in Prague.

[2] Anderson, E. J., Hu, X., Winchester, D.: Forward Contracts in Electricity Markets: The Australian Experience, Energy Policy, Vol. 35 (2007), Elsevier.

[3] Adamec, M., Indráková, M., Karajica, M.: European Scheduling Overview (Training document ČEZ a.s.), 2007. 
[4] Haas, R., Glachant, J. M., Keseric, N., Perez, Y.: Electricity Market. ETSO European Transmission System Operator

Marek Adamec

e-mail: adamem3@fel.cvut.cz

Michaela Indráková

e-mail: indram1@fel.cvut.cz

Mirza Karajica

e-mail:karajm1@fel.cvut.cz

Department of Economics, Management and Humanities

Czech Technical University in Prague

Faculty of Electrical Engineering

Zikova 4

16627 Praha, Czech Republic 